\title{
A Review of Methodological Approaches and Modeling Techniques in Service Quality Evaluation of Surface Transportation during the Last Decade
}

\author{
Nayeem Islam* \\ Department of Civil Engineering, Bangabandhu Sheikh Mujibur Rahman Science \& Technology University, Gopalganj-8100, \\ Bangladesh
}

Received: October 15, 2021, Revised: December 11, 2021, Accepted: December 13, 2021, Available Online: December 18, 2021

\begin{abstract}
During the duration of the last decade, a growing interest has been noticed among transport practitioners and researchers to better understand the concept of service quality in the field of surface transportation and identify important service quality (SQ) attributes of different transportation services since these results have implications for transport managers. Due to advancements in computer technology and the availability of software packages, researchers are better able to extract meaningful results from passengers' opinions collected through stated preference surveys and communicate their findings to transport managers looking to ameliorate SQ to boost ridership on a limited budget. Since the concept of SQ is itself complex owing to the nature of the service itself compared to a tangible product and characteristics of SQ attribute, different advanced modelling techniques based on multivariate analysis, machine learning, and artificial intelligence paradigms have become popular tools among researchers. This paper aims to summarize the trends of the SQ research in the field of surface transportation during the last decade with a focus on the methodological approaches and modelling techniques and delineate future directions for research in this field.
\end{abstract}

Keywords: Service Quality, Surface Transportation, Stated Importance, Neural Networks, Decision Trees, SEM.

This work is licensed under a Creative Commons Attribution-Non Commercial 4.0 International License.

\section{Introduction}

Traditionally, assessment of service quality (SQ) of transportation has been carried out from the point of view of transport operators and managers. Transport operators need to continuously assess the performance of their service to ensure the efficiency, effectiveness, and quality of their service. This enables the transport operators to keep attracting passengers and remain competitive in the industry. Generally, performance evaluation of transportation by transport managers considers the effectiveness and efficiency of the service in terms of cost. The inherent drawbacks of using such performance-based service quality measures are obvious. This then is the area where the interests of different stakeholders (researchers, transport practitioners, and operators) in the domain of public transportation intersect. Researchers develop models of service quality that afford transport operators and practitioners a deeper insight into the SQ paradigm.

Transport operators benefit from knowing about the SQ attributes which influence passengers when they make the holistic evaluation of SQ in several ways. It is often necessary for transport operators to make key investments decisions based on limited funds for improving SQ. It is not feasible for operators to improve different aspects of the service simultaneously. Hence operators must expand their limited funds on SQ attributes perceived by passengers as being the most important for overall transport SQ. Additionally, the ranking of the most important SQ attributes enables transport operators to formulate a plan for the staged development of the transport service.

Transport practitioners are interested in promoting public transportation as a more sustainable alternative to automobiles. The proliferation of automobiles as an affordable private mode of transportation is posing serious problems for urban mobility by contributing to chronic congestion, air pollution and declining role of more sustainable public transportation.

However, modeling SQ in the domain of transportation is challenging for several reasons. The SQ concept is itself abstract and complex; perception heterogeneity of passengers is often a key determinant of SQ; absence of a unanimous list of SQ attributes for all types of transportation and subjective nature of the data.

Even though assessment of SQ of transportation has become a popular topic among researchers for a substantial period [1],[2], it was only during the duration of the last decade researchers employed data mining and other sophisticated mathematical models have been employed for analysing SQ of transportation due to the development and availability of different software packages. These advanced modeling approaches offer certain advantages over traditional modeling approaches. Moreover, the last decade has seen a large volume of work related to SQ assessment of surface transportation particularly the public transit industry using stated preference (SP) surveys whereas previous studies mainly focused on the aviation industry.

This then is the premise where present work is based. Therefore, the objective of this research will be to provide a concise review of the state-of-the-art procedural approaches and mathematical modeling techniques which researchers have incorporated in the realm of SQ assessment of surface transportation during the last decade. To achieve this objective, studies which have used different mathematical modeling and data mining techniques in the domain of transportation SQ were analysed based on their data collection procedure, methodological approaches, modeling procedures, presentation of results, and important inferences. An additional objective of this work is to delineate future research directions for this topic. This paper will be structured in five sections: Section 2 discusses 
the concept of service quality, Section 3 furnishes some issues associated with research in this domain with respect to survey methodology, Section 4 provides a critique of the modeling techniques used by different researchers, Section 5 draws conclusions from this review and discusses future directions in this domain of research.

\section{Concept of Service Quality}

According to some researchers, the SQ concept is complex [3],[4]. This explains the application of a wide variety of methodological approaches and modeling techniques in this domain. This complexity is primarily attributed to the distinct properties of a service as compared to a product. Firstly, the output of a service cannot be measured easily like that of a product. Secondly, how an individual perceives a service is primarily a function of his/her socio-economic status, tastes, and preferences as well as expectations. Lastly, a service is first advertised, sold, and then produced and consumed simultaneously unlike a product that is produced at first, then advertised and sold before its eventual consumption.

Moreover, the following characteristics of the SQ attributes make assessments of SQ of transportation a challenging proposition for researchers:

- Number of Attributes: There is no consensus among researchers whether an exhaustive list of SQ attributes exists for the domain of transportation despite the claims of Berry of a generic list of attributes [5].

- Type of Attributes: Researchers have agreed that all SQ attributes do not have the same impact on overall SQ and therefore can be categorized into groups. According to UNE-EN 13186 standard SQ attributes can be grouped into three categories: basic, proportional, and attractive [6]. The Transit Capacity and Quality of Service Manual and Eboli \& Mazzulla divide SQ attributes into two groups: ones which are basic and ones which are not basic [7],[8]. In all cases, the first category of attributes (basic) are expected by passengers as prerequisites of the service. The extent of evaluation of the latter category or categories of attributes by passengers depends on whether they are satisfied by the 'basic' attributes or not.

- Nature of SQ Attributes: Previous studies have used both qualitative [9] and quantitative attributes [10] or a mixture of both [2],[11].

- Specificity of Attributes: Researchers have concluded that attributes should be selected with regard to the context of the study. Pilot surveys focused group discussions, literature reviews, counsel with experts, academicians are utilized for drawing a list of attributes specific to the geographical location, passengers' socio-economic backgrounds, type of service, mode of transport, and mode choices available to passengers. The solution to the heterogeneity of passengers and service has been addressed by interactions between socioeconomic factors and service aspects [12] market segmentation [13]-[16], service segmentation [12] and clustering [17].

- Perspective of Assessment: As mentioned previously, most researchers agree that SQ should be measured from the point of view of passengers since a considerable difference exists between passenger perceptions and the judgment of experts [10],[18]. However, according to Thomas et al. [19] as cited by Nathanail [2] about some service aspects like safety, perception, and preference of passengers cannot be relied upon.

\section{Survey Methodology}

Different approaches may be employed to estimate the relative importance a customer attaches to each of the attributes which are related to service quality. In the stated importance methods, passengers are asked to rate each attribute on an importance scale. On the other hand, derived importance methods statistically analyse the relationship of individual attributes with overall satisfaction to derive the importance of each attribute. The stated importance method is simpler and more intuitive of the two methods but is not without some drawbacks. Often the length of stated importance surveys can limit the response rate and many passengers are unable to discriminate between the importance of different attributes which impact overall service quality. Thus, researchers using data mining techniques have often preferred derived importance methods based on stated preference surveys since data mining techniques are able to generate a ranking of the most important explanatory variables for each developed model.

Therefore, the most widely used method for measuring service quality of transportation involves asking the users to rate different aspects of the used service in a questionnaire survey called customer satisfaction surveys (CSS). In different studies, users of the transport service were provided with questionnaires where passengers generally expressed their perceptions of performance on a Likert scale, identified or rated the most important SQ attributes among the SQ attributes given in the survey, and were often asked to rate overall transportation SQ on a Likert scale. Different numeric Likert scales (0-10; 1-10; 1-5; $1-6,1-7,1-9,-2$ to +2$)$ are found in the literature which is often complemented by linguistic/qualitative scales for ease of understanding by passengers and there is no consensus among researchers with regard to the format of the numeric or semantic Likert scale which would make the survey more effective and inclusive. Machado-León et al. used different numeric Likert scales for different sections of the same questionnaire, so passengers are able to better differentiate between attribute scores [20]. For example, de Oña et al. used a three-point semantic scale (poor, fair, and good) for obtaining passengers' perception of performance and used a numeric 10 point scale for collecting information about the importance of SQ attributes [21]. Other studies asked passengers to select the attributes they considered as important sparing them from the tedious routine of having to rate all the SQ attributes individually [16],[22]-[26]. Moreover, researchers using decision trees reduced the dependent and explanatory variables in a semantic scale (POOR, FAIR, and GOOD) for ease of modeling [13],[15].

\subsection{Sample Size}

Sample size used in previous studies varied widely from one study to another. Pakdil \& Kurtulmuşoğlu [27], Kurtulmuşoğlu et al. [28] used the sampling approach recommended by De Vaus [29] to compute sample size. Deb \& Ahmed [9] computed the minimum sample size based on the equation proposed by Johnson \& Wichern [30]. In order to ensure the results of the sample population can be used to draw conclusions about public transit users, Mahmoud \& Hine [31] used the guidelines of Bartlett et al. [32]. Jomnonkwao \& Ratanavaraha [33] used the guidelines of Stevens [34] who set the minimum number of samples to be at least 15 times the number of observed variables if maximum likelihood estimation is used. Some studies [14],[35] sampled 3-4\% of the population. The sample size used in different studies are recorded in Table 1. 
Table 1 Summary of Research in Surface Transportation during Last Decade

\begin{tabular}{|c|c|c|c|c|c|c|c|}
\hline References & Industry & Country & Region & $\begin{array}{c}\text { Valid } \\
\text { Surveys }\end{array}$ & Scale Used & Type of Scale & Modeling \\
\hline Bordagaray et al. [12] & Bus Transit & Spain & $\begin{array}{c}\text { Santand } \\
\text { er }\end{array}$ & 266 & $1-5$ & Likert Scale & Ordered probit models \\
\hline Cheng et al. [41] & Bus Transit & China & Xianbei & 291 & $1-5$ & Likert Scale & SEM \\
\hline Deb \& Ahmed [9] & Bus Transit & India & Agartala & 400 & $1-9$ & Likert Scale & SEM \\
\hline $\begin{array}{l}\text { Pakdil \& Kurtulmuşoğlu } \\
\text { [27] }\end{array}$ & Intercity Bus & Europe & $\begin{array}{c}\text { Not } \\
\text { mention } \\
\text { ed }\end{array}$ & 500 & $1-5$ & Likert Scale & QFD \\
\hline Kurtulmuşoğlu et al. [28] & Intercity Bus & $\begin{array}{l}\text { Not } \\
\text { mentioned }\end{array}$ & $\begin{array}{l}\text { Not } \\
\text { mention } \\
\text { ed }\end{array}$ & 285 & 5 Layer & $\begin{array}{c}\text { Triangular Fuzzy } \\
\text { Number }\end{array}$ & Fuzzy QFD \\
\hline Jen et al. [43] & Intercity Bus & Taiwan & Taipei & 747 & $1-5$ & Likert Scale & SEM \\
\hline $\begin{array}{l}\text { Jomnonkwao and } \\
\text { Ratanavaraha [33] }\end{array}$ & $\begin{array}{l}\text { Sight seeing } \\
\text { bus }\end{array}$ & Thailand & N.A. & 3387 & $1-7$ & Likert Scale & SEM \\
\hline Mahmoud \& Hine [31] & Bus Transit & UK & Belfast & 512 & $1-10$ & Likert Scale & Binary logistic regression \\
\hline Rojo et al. [46] & Intercity Bus & Spain & N.A. & 1011 & $1-5$ & Likert Scale & $\begin{array}{c}\text { Ordered Logit and probit } \\
\text { model }\end{array}$ \\
\hline Rojo et al. [48] & Intercity Bus & Spain & $\begin{array}{l}\text { Castilla } \\
\text { y León }\end{array}$ & 375 & N.A. & SP Experiment & $\begin{array}{l}\text { Multinomial, hierarchial } \\
\text { and mixed logit models }\end{array}$ \\
\hline Chou et al. [38] & $\begin{array}{l}\text { High Speed } \\
\text { Rail }\end{array}$ & Taiwan & N.A. & 1235 & $1-7$ & Likert Scale & SEM \\
\hline de Oña et al. [21] & Bus transit & Spain & Granada & 858 & Not mentioned & Not mentioned & Decision Tree \\
\hline de Oña \& de Oña [15] & Bus transit & Spain & Granada & 3182 & $0-10$ & Likert Scale & Decision Tree \\
\hline de Oña \& de Oña [26] & Bus transit & Spain & Granada & 3664 & $0-10$ & Likert Scale & Decision Tree \\
\hline de Oña et al. [35] & Rail Transit & Italy & Milan & 16647 & $1-10$ & Likert Scale & Decision Tree \\
\hline de Oña et al. [14] & Rail transit & Italy & Milan & 7333 & $1-10$ & Likert Scale & Decision Tree \\
\hline de Oña et al. [17] & Bus transit & Spain & Granada & 3664 & $0-10,1-5$ & Likert Scale & Decision Tree \\
\hline Machado-León et al. [20] & Rail Transit & Algiers & Algeria & 1454 & $0-10,1-5$ & Likert Scale & $\begin{array}{c}\text { Importance-Performance } \\
\text { Analysis and Decision } \\
\text { Tree }\end{array}$ \\
\hline de Oña et al. [36] & Bus transit & Spain & Granada & 858 & $0-10$ & Likert Scale & Decision Tree and ANN \\
\hline Garrido et al. [37] & Bus transit & Spain & Granada & 858 & $0-10$ & Likert Scale & ANN \\
\hline Hadiuzzaman et al. [16] & Intercity train & Bangladesh & N.A. & 1037 & $1-5$ & Likert Scale & SEM \\
\hline Hadiuzzaman et al. [22] & Intercity train & Bangladesh & N.A. & 1590 & $1-5$ & Likert Scale & ANFIS \\
\hline Hadiuzzaman et al. [23] & Bus transit & Bangladesh & Dhaka & 655 & $1-5$ & Likert Scale & SEM \\
\hline Islam et al. [24] & Bus transit & Bangladesh & Dhaka & 655 & $1-5$ & Likert Scale & PNN and ANFIS \\
\hline Islam et al. [25] & Bus transit & Bangladesh & Dhaka & 655 & $1-5$ & Likert Scale & GRNN, PNN and PRNN \\
\hline Machado-León et al. [40] & $\begin{array}{l}\text { Light Rail } \\
\text { Transit }\end{array}$ & Spain & Seville & 3211 & $0-10,1-5$ & Likert Scale & SEM \\
\hline Yilmaz \& Ari [39] & $\begin{array}{l}\text { Inter-city high } \\
\text { speed rail }\end{array}$ & Turkey & N.A. & 352 & $1-5$ & Likert Scale & SEM \\
\hline Joewono et al. [44] & $\begin{array}{l}\text { Road based } \\
\text { public } \\
\text { transport }\end{array}$ & Indonesia & $\begin{array}{l}\text { Differen } \\
\text { t cities }\end{array}$ & 1482 & $1-5$ & Likert Scale & SEM \\
\hline Nwachukwu [45] & Bus transit & Nigeria & Abuja & 300 & $1-5$ & Likert Scale & $\begin{array}{c}\text { Principal Component } \\
\text { Analysis }\end{array}$ \\
\hline Hu et al. [42] & Bus transit & China & Nanjing & 958 & $1-5$ & Likert Scale & $\begin{array}{c}\text { SEM and multinomial } \\
\text { logit model }\end{array}$ \\
\hline
\end{tabular}




\section{Modeling Techniques}

de Oña \& de Oña classified methodological approaches in measuring SQ into two categories: (i) disaggregated models and (ii) aggregated models [13]. In the disaggregated model the SQ attributes are analyzed individually but in aggregated models, SQ attributes are combined to obtain a service quality index. While aggregated models offer the advantage that it can be used to compare different transportation services, aggregated models shortlist the significant SQ attributes for the transport manager on a limited budget to improve upon. Consequently, disaggregated models have been preferred by researchers in the last decade, the time period of interest in this review paper. Among the different statistical and machine learning techniques the following have been mostly used by researchers: decision trees (DT), neural networks, structured equation modeling (SEM) and factor analysis, and different types of logit models. Quality Function Deployment (QFD) and Fuzzy QFD have only been introduced by Pakdil \& Kurtulmusoglu and Kurtulmuşoğlu et al. respectively [27]-[28].

\subsection{Decision Trees}

Before being applied in the domain of SQ studies, decision trees were applied to both regression and classification problems in traffic engineering. Decision trees divide the predictor space into a number of simple regions. Prediction for a new observation is made by taking into account the mean or mode of the training observations in the region where the new observation belongs. A classification tree is utilized when the value of the target variable is discrete whereas a regression tree is utilized when the value of the target variable is continuous. The main benefit offered by decision trees is that there are no underlying assumptions between independent and dependent variables. The visualization of a decision tree model is also easy to understand and interpret. This is an important feature of decision trees since transport managers are generally non-technical people and can understand the models easily. Moreover, useful decision rules can be extracted from the models. A decision rule is created by following a path from the root node to the terminal node of a decision tree model. Decision trees can handle many both numerical and categorical variables as well as a large number of explanatory variables without normalization. The standardized importance of attributes can also be extracted from decision trees.

However, decision tree models are not typically robust, have lower accuracy rates, do not offer backtracking techniques, or provide statistical significance of variables [36]. Moreover, studies using decision trees have not specifically mentioned the algorithms used [13],[21].

\subsection{Neural Networks}

Neural networks are models which process information closely mimicking the process in the human brain. It is capable of supervised learning even when noise is present. The neural network is composed of neurons which are primary information processing units. These neurons are organized into several layers and connected to each other through synaptic weights which represent the strength of interaction between each pair of neurons. Activation functions calculate the potential of each neuron. Different types of neural networks exist: Artificial Neural Networks (ANN), Generalized Regression Neural Network (GRNN), Probabilistic Neural Network (PNN), and Pattern Recognition Neural Network (PRNN), Adaptive Neuro Fuzzy Inference System (ANFIS).
A number of advantages of using neural networks have been reported by researchers higher precision, more stability for determining attribute importance, capability for handling multicollinearity [36]-[37]. The main drawback of using neural networks reported is mainly related to the time necessary to train and the cumbersome routine needed to determine variable importance.

The different types of neural networks employed in SQ studies and often compared to each other or other techniques include ANN [37], comparison between ANN and DT [36] comparison between ANFIS and PNN [24], comparison between PNN, PRNN, and GRNN [25] and ANFIS [22].

\subsection{SEM and Factor Analysis}

SEM is an integration of measurement theory, factor analysis, multiple regression, simultaneous equations, and path analysis. It has gained prominence among researchers in the domain of SQ studies primarily because it is able to identify which observed variables are good indicators of the latent variables. SEM consists of measurement and structural models. The task of the measurement model also called confirmatory factor analysis is to determine the correlation between observed variables and latent variables. The structural model is used to determine the strength and direction of relations between latent variables.

SEM has been applied to different transportation services: high-speed rail [38]-[39], light rail transit [40], train service in developing countries [24], bus transit [9],[41]-[42], intercity bus [43] and combination of different types of urban public transport [44].

In addition factor analysis which is normally used as a preparatory step for SEM was applied separately as a modeling technique for different SQ studies in sightseeing bus service [33] and city bus service [45].

\subsection{Logit Models}

Discrete choice models explain how passengers choose between different alternatives. However, to fit within the model framework, the choice set needs to demonstrate three characteristics:

- $\quad$ only one alternative can be chosen by passengers.

- list of alternatives in the choice set needs to be exhaustive.

- there needs to be a finite number of alternatives available to passengers.

Generally stated preference surveys in the field of SQ assessment of transportation provide passengers with choices which are ordered: 'very satisfied' is better than 'satisfied' and the choices are not necessarily independent of one another. Hence ordered logit and probit models are therefore more suited to stated preference experiment data of this type and have been applied in SQ studies in inter-city bus service [46]-[47], bus transit [12]. Other forms of logit model that have been used are multinomial logit models for city bus service [48] and multinomial, hierarchical and mixed logit models for inter-city bus service [48]. These models have been used for determining the weight of different service aspects.

\subsection{QFD and Fuzzy QFD}

QFD is a process which attempts to capture the needs of the customers and respond to those needs through specific plans for improving the product or service in question. The customer requirements are translated to measurable design targets using 
QFD. A unique feature of the QFD process is that it also utilizes transport operators' technical knowledge besides passengers' perceptions [27]. QFD process flows through six distinct phases which are interconnected within a House of Quality (HOQ) diagram: (1) customer needs and expectations, (2) planning matrix, (3) technical requirements, (4) relationship matrix, (5) technical correlation matrix, and (6) customer evaluations. However, since QFD was originally adapted to manufacturing industries, and SQ by nature is abstract and fuzzy, fuzzy set theory was employed by Kurtulmuşoğlu et al. to improve the planning matrix, relationship matrix, and technical correlation matrix [28].

\section{Discussion and Future Research Directions}

Despite the large volume of work already accomplished in the last decade, there is considerable work to be done in the domain of SQ of surface transportation services. For example, a careful view of Table 1 reveals that very few studies have focused on inter-city transportation services. Moreover, very few studies actually compare the efficacy of different modeling techniques in order to find the optimum model in the domain of SQ studies [24]-[25],[36]. Also, it is noticeable that despite the use of machine learning models like decision trees in different SQ studies, researchers are yet to use any ensemble models like Random Forests or more fine-tuned applications of decision trees like gradient boosted decision tree models. The different attempts by researchers in developing countries to evaluate the service quality of public transportation are commendable but still, the volume of research coming from developing countries is considerably low. Also, researchers need to find out how they can collect greater volumes of data using online surveys making research results more meaningful.

In this paper, an attempt has been made to capture the contemporary thinking and modeling techniques used by researchers to evaluate the service quality of surface transportation services in the last decade. This paper also tried to focus on the algorithms that have gained popularity among researchers due to the advancement made in computer technology and the widespread availability of several powerful software packages. Finally, it is expected that the insight provided by this paper will be useful to all stakeholders in the domain of transportation services and researchers will contemplate the future directions proposed in this paper.

\section{Conclusions}

The preceding discussion shows that a plethora of attempts and modeling methodologies have been used by researchers to better understand the SQ paradigm convey useful information for transport managers to work on. The variety of attempts point towards the complexity of the SQ concept and the wealth of modeling techniques that are available to the researchers.

However, some trends have become evident in the last decade in SQ studies. Firstly, researchers have preferred the stated preference surveys to collect satisfaction/ perception and importance rating of different SQ attributes from passengers using numerical Likert scales. Secondly, researchers are increasingly using multivariate analysis techniques like SEM, machine learning, and artificial intelligence-based paradigms like neural networks and decision trees and ordered choice models. These models are enabling researchers, transport managers deeper insight into the SQ paradigm than simpler regression models. It is also possible to deduce the importance of independent variables from these models since it has been shown that asking passengers to rate the importance of SQ attributes often produces unrealistic results [35],[50]. Thirdly, researchers are taking into account the perception heterogeneity of the SQ data and introducing different innovative techniques like clustering which can help transport managers to introduce personalized market in surface transportation services like in the aviation industry.

\section{References}

[1] Cavana, R. Y., Corbett, L. M., \& Lo, Y. G., 2007. Developing zones of tolerance for managing passenger rail service quality. International Journal of Quality \& Reliability Management. 24(1), pp.7-31.

[2] Nathanail, E., 2008. Measuring the quality of service for passengers on the Hellenic railways. Transportation Research Part A: Policy and Practice, 42(1), pp.48-66.

[3] Carman, J.M., 1990. Consumer perceptions of service quality: an assessment of T. Journal of Retailing, 66(1), p.33.

[4] Parasuraman, A., Zeithaml, V.A. and Berry, L.L., 1985. A conceptual model of service quality and its implications for future research. Journal of Marketing, 49(4), pp.41-50.

[5] Parasuraman, A., Zeithaml, V.A. and Berry, L., 1988. SERVQUAL: A multiple-item scale for measuring consumer perceptions of service quality. Journal of Retailing, 64(1), pp.12-40.

[6] UNE-EN 13816, 2003. Transportation. Logistics and Services. Public Passenger Transport.Service Quality Definition, Targeting and Measurement, AENOR, Madrid.

[7] Kittelson \& Associates, United States. Federal Transit Administration, Transit Cooperative Research Program and Transit Development Corporation, 2003. Transit capacity and quality of service manual (Vol. 42). Transportation Research Board.

[8] Eboli, L. and Mazzulla, G., 2008. Willingness-to-pay of public transport users for improvement in service quality. European Transport $\backslash$ Trasporti Europei, 38, pp.107-118.

[9] Deb, S. and Ahmed, M.A., 2018. Determining the service quality of the city bus service based on users' perceptions and expectations. Travel Behaviour and Society, 12, pp.1-10.

[10] Das, S. and Pandit, D., 2015. Determination of level-of-service scale values for quantitative bus transit service attributes based on user perception. Transportmetrica A: Transport Science, 11(1), pp.1-21.

[11] Basu, D. and Hunt, J.D., 2012. Valuing of attributes influencing the attractiveness of suburban train service in Mumbai city: A stated preference approach. Transportation Research Part A: Policy and Practice, 46(9), pp.1465-1476.

[12] Bordagaray, M., dell'Olio, L., Ibeas, A. and Cecín, P., 2014. Modelling user perception of bus transit quality considering user and service heterogeneity. Transportmetrica A: Transport Science, 10(8), pp.705-721.

[13] de Oña, R. and de Oña, J., 2015. Analysis of transit quality of service through segmentation and classification tree techniques. Transportmetrica A: Transport Science, 11(5), pp.365-387.

[14] De Ona, J., de Oña, R., Eboli, L. and Mazzulla, G., 2015. Heterogeneity in perceptions of service quality among groups of railway passengers. International Journal of Sustainable Transportation, 9(8), pp.612-626.

[15] De Oña, R. and De Oña, J., 2013. Analyzing transit service quality evolution using decision trees and gender segmentation. WIT transactions on the built environment, 130, pp.611-621.

[16] Hadiuzzaman, M., Farazi, N.P., Hossain, S. and Malik, D.G., 2019. An exploratory analysis of observed and latent variables affecting intercity train service quality in developing countries. Transportation, 46(4), pp.1447-1466.

[17] de Oña, J., de Oña, R. and López, G., 2016. Transit service quality analysis using cluster analysis and decision trees: a step 
forward to personalized marketing in public transportation. Transportation, 43(5), pp.725-747.

[18] Das, S. and Pandit, D., 2012. Methodology to identify the gaps in the level of service provided for urban bus transit: Case study Kolkata. Spandrel, 4(Spring), pp.59-71.

[19] Thomas, L.J., Rhind, D.J. and Robinson, K.J., 2006. Rail passenger perceptions of risk and safety and priorities for improvement. Cognition, Technology \& Work, 8(1), pp.67-75.

[20] Machado-León, J.L., de Oña, R., Baouni, T. and de Oña, J., 2017. Railway transit services in Algiers: priority improvement actions based on users perceptions. Transport Policy, 53, pp.175-185.

[21] De Oña, J., De Oña, R. and Calvo, F.J., 2012. A classification tree approach to identify key factors of transit service quality. Expert Systems with Applications, 39(12), pp.11164-11171.

[22] Hadiuzzaman, M., Malik, D.G., Barua, S., Qiu, T.Z. and Kim, A., 2019. Modeling passengers' perceptions of intercity train service quality for regular and special days. Public Transport, 11(3), pp.549-576.

[23] Hadiuzzman, M., Das, T., Hasnat, M.M., Hossain, S. and Rafee Musabbir, S., 2017. Structural equation modeling of user satisfaction of bus transit service quality based on stated preferences and latent variables. Transportation Planning and Technology, 40(3), pp.257-277.

[24] Islam, R., Musabbir, S.R., Ahmed, I.U., Hadiuzzaman, M., Hasnat, M. and Hossain, S., 2016. Bus service quality prediction and attribute ranking using probabilistic neural network and adaptive neuro fuzzy inference system. Canadian Journal of Civil Engineering, 43(9), pp.822-829.

[25] Islam, M.R., Hadiuzzaman, M., Banik, R., Hasnat, M.M., Musabbir, S.R. and Hossain, S., 2016. Bus service quality prediction and attribute ranking: a neural network approach. Public transport, 8(2), pp.295-313.

[26] De Oña, J. and De Oña, R., 2015. Quality of service in public transport based on customer satisfaction surveys: A review and assessment of methodological approaches. Transportation Science, 49(3), pp.605-622.

[27] Pakdil, F. and Kurtulmusoglu, F.B., 2014. Improving service quality in highway passenger transportation: a case study using quality function deployment. EJTIR, 14(4), pp.375-393.

[28] Kurtulmuşoğlu, F.B., Pakdil, F. and Atalay, K.D., 2016. Quality improvement strategies of highway bus service based on a fuzzy quality function deployment approach. Transportmetrica A: Transport Science, 12(2), pp.175-202.

[29] De Vaus, D., \& de Vaus, D. (2013). Surveys In Social Research (6th ed.). Routledge.

[30] Johnson, R.A. and Wichern, D.W., 2014. Applied multivariate statistical analysis (Vol. 6). London, UK:: Pearson.

[31] Mahmoud, M. and Hine, J., 2016. Measuring the influence of bus service quality on the perception of users. Transportation Planning and Technology, 39(3), pp.284-299.

[32] Kotrlik, J.W.K.J.W. and Higgins, C.C.H.C.C., 2001. Organizational research: Determining appropriate sample size in survey research appropriate sample size in survey research. Information Technology, Learning, and Performance Journal, 19(1), p.43-50.

[33] Jomnonkwao, S. and Ratanavaraha, V., 2016. Measurement modelling of the perceived service quality of a sightseeing bus service: An application of hierarchical confirmatory factor analysis. Transport Policy, 45, pp.240-252.
[34] Stevens, J., 1966. Applied Multivariate Statistics for the Social Sciences. Lawrence Erlbaum Associates, NJ.

[35] De Oña, R., Eboli, L. and Mazzulla, G., 2014. Key factors affecting rail service quality in the Northern Italy: a decision tree approach. Transport, 29(1), pp.75-83.

[36] de Oña, J., de Oña, R. and Garrido, C., 2017. Extraction of attribute importance from satisfaction surveys with data mining techniques: a comparison between neural networks and decision trees. Transportation Letters, 9(1), pp.39-48.

[37] Garrido, C., De Oña, R. and De Oña, J., 2014. Neural networks for analyzing service quality in public transportation. Expert Systems with Applications, 41(15), pp.6830-6838.

[38] Chou, P.F., Lu, C.S. and Chang, Y.H., 2014. Effects of service quality and customer satisfaction on customer loyalty in highspeed rail services in Taiwan. Transportmetrica A: Transport Science, 10(10), pp.917-945.

[39] Yilmaz, V. and Ari, E., 2017. The effects of service quality, image, and customer satisfaction on customer complaints and loyalty in high-speed rail service in Turkey: a proposal of the structural equation model. Transportmetrica A: Transport Science, 13(1), pp.67-90.

[40] Machado-León, J.L., de Oña, R. and de Oña, J., 2016. The role of involvement in regards to public transit riders' perceptions of the service. Transport Policy, 48, pp.34-44.

[41] Cheng, X., Cao, Y., Huang, K. and Wang, Y., 2018. Modeling the satisfaction of bus traffic transfer service quality at a highspeed railway station. Journal of Advanced Transportation, 2018.

[42] Hu, X., Zhao, L. and Wang, W., 2015. Impact of perceptions of bus service performance on mode choice preference. Advances in Mechanical Engineering, 7(3), p.1687814015573826.

[43] Jen, W., Tu, R. and Lu, T., 2011. Managing passenger behavioral intention: an integrated framework for service quality, satisfaction, perceived value, and switching barriers. Transportation, 38(2), pp.321-342.

[44] Joewono, T.B., Tarigan, A.K. and Susilo, Y.O., 2016. Roadbased public transportation in urban areas of Indonesia: what policies do users expect to improve the service quality? Transport policy, 49, pp.114-124.

[45] Nwachukwu, A.A., 2014. Assessment of passenger satisfaction with intra-city public bus transport services in Abuja, Nigeria. Journal of Public Transportation, 17(1), pp.99-119.

[46] Rojo, M., Gonzalo-Orden, H., dell'Olio, L. and Ibeas, A., 2011, February. Modelling gender perception of quality in interurban bus services. In Proceedings of the Institution of Civil Engineers-Transport (Vol. 164, No. 1, pp. 43-53). Thomas Telford Ltd.

[47] Rojo, M., dell'Olio, L., Gonzalo-Orden, H. and Ibeas, Á., 2013. Interurban bus service quality from the users' viewpoint. Transportation Planning and Technology, 36(7), pp.599-616.

[48] Dell'Olio, L., Ibeas, A. and Cecin, P., 2011. The quality of service desired by public transport users. Transport Policy, 18(1), pp.217-227.

[49] Rojo, M., Gonzalo-Orden, H., dell'Olio, L. and Ibeas, Á., 2012. Relationship between service quality and demand for interurban buses. Transportation Research Part A: Policy and Practice, 46(10), pp.1716-1729.

[50] Weinstein, A., 2000. Customer satisfaction among transit riders: How customers rank the relative importance of various service attributes. Transportation Research Record, 1735(1), pp.123132. 